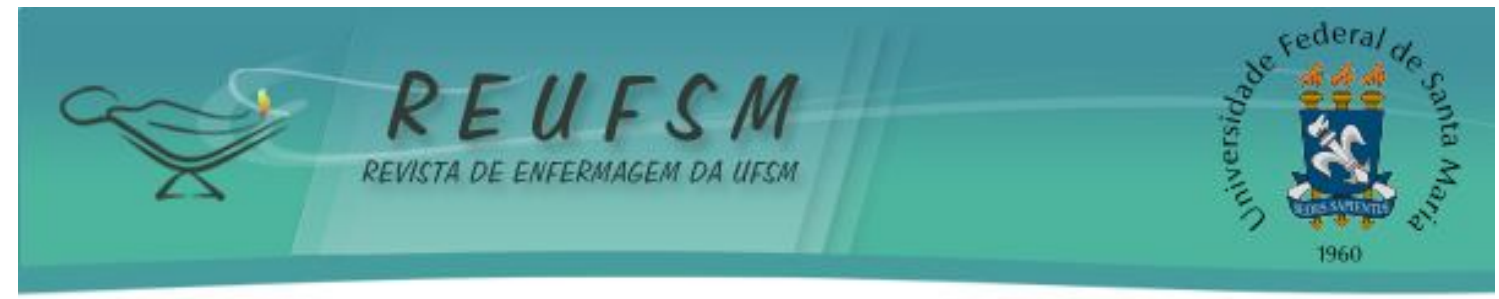

ARTIGO ORIGINAL

\title{
COLETA DE CITOPATOLÓGICO DE COLO UTERINO: SABERES E PERCEPÇÕES DE MULHERES QUE REALIZAM $O$ EXAME
}

\section{CYTOLOGICAL SAMPLING OF THE UTERINE CERVIX: KNOWLEDGE AND PERCEPTIONS OF WOMEN WHO GO THROUGH THE EXAM}

\section{COLECTA DE CITOPATOLÓGICO DE COLON UTERINO: CONOCIMIENTOS Y PERCEPCIONES DE MUJ ERES QUE REALIZAN EL EXAMEN}

\author{
Simone Wünsch ${ }^{1}$ \\ Stefanie Griebeler Oliveira ${ }^{2}$ \\ Raquel Pötter Garcia ${ }^{3}$ \\ Izaura Bica Domingues ${ }^{4}$
}

RESUMO: Este estudo objetivou investigar os saberes e as percepções de mulheres em relação à coleta de exame citopatológico do colo de útero. Foi realizada uma pesquisa qualitativa de caráter descritivo e exploratório em uma cidade do interior do sul do Brasil. 0 estudo foi realizado com mulheres que buscaram o atendimento para a realização do exame em três Unidades de Saúde da Família. Para definição do número de participantes, utilizou-se o critério de saturação em cada Unidade de Saúde da Família. Realizou-se a coleta de dados por meio de entrevistas e, posteriormente, análise temática. As mulheres apresentam conhecimento acerca do objetivo do exame. Além disso, afloraram sentimentos como vergonha e constrangimento, os quais são construídos culturalmente e se constituem barreiras para a realização da coleta do citopatológico de colo uterino.

Descritores: Enfermagem; Prevenção de câncer de colo uterino; Saúde da mulher; Cultura.

ABSTRACT: This study aimed to investigate the knowledge and the perceptions of women regarding uterine cervix cytological sampling. A qualitative research, characterized as exploratory and descriptive was conducted in a countryside city in the South of Brazil. Such study was carried out with women who looked for medical assistance to go through the test, in three Family Health Units. Saturation criterion was considered, regarding each FHU, as for definition of the number of participants. Data collection was accomplished through interviews, which were followed by thematic analysis. The women present knowledge about the aim of the exam. Besides, feelings such as shame and embarrassment emerged, which are culturally built and established as barriers for the test.

Descriptors: Nursing; Cervix neoplasms prevention; Women's health; Culture.

\footnotetext{
${ }^{1}$ Enfermeira. Mestranda do Programa de Pós Graduação em Enfermagem (PPGEnf) da Universidade Federal de Santa Maria (UFSM). Pós Graduada em Saúde Pública. Membro do Grupo de Pesquisa Cuidado Saúde e Enfermagem. E-mail: simone.wunsch@gmail.com

${ }^{2}$ Enfermeira. Mestre em Enfermagem. Doutoranda em Enfermagem pela Universidade Federal do Rio Grande do Sul (UFRGS). Membro dos Grupos de Pesquisa: Cuidado Saúde e Enfermagem (UFSM); e do Grupo de Estudos Culturais na Educação em Saúde e Enfermagem (UFRGS). Bolsista Capes. E-mail: stefaniegriebeler@yahoo.com.br

3 Enfermeira. Mestranda do Programa de Pós-Graduação em Enfermagem (PPGEnf) da Universidade Federal de Santa Maria (UFSM). Membro do Grupo de Pesquisa Cuidado, Saúde e Enfermagem. E-mail: raquelpotter_@hotmail.com

4 Enfermeira - Pós-graduanda em Saúde da Família - UFCSPA/Ministério da Saúde. Especialista em Saúde Pública e Educação para Enfermagem. Enfermeira da ESF II Vila Trinta São Luiz Gonzaga/RS. E-mail: izaurabica@yahoo.com.br
} 


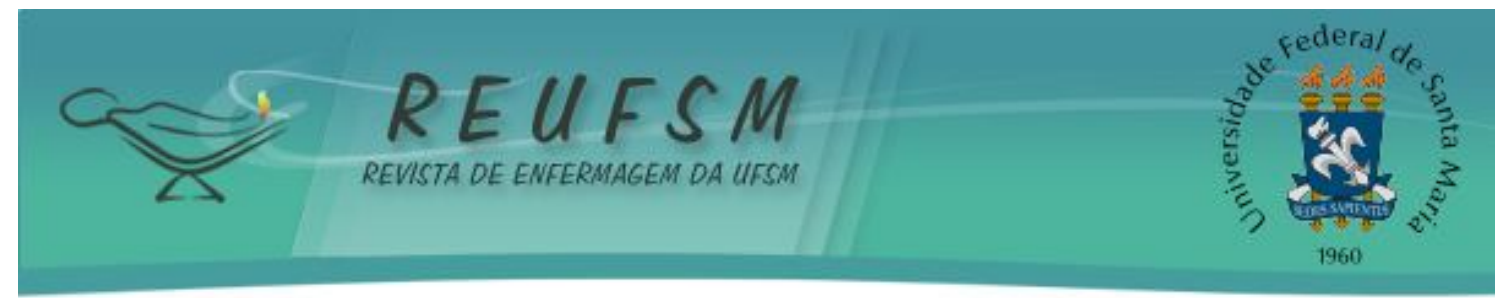

RESUMEN: Este estudio objetivó investigar los conocimientos y las percepciones de mujeres en relación a la colecta de examen citopatológico del colon uterino. Fue realizada una pesquisa cualitativa de carácter descriptivo y exploratorio en una ciudad del interior del Sur del Brasil. El estudio fue realizado con mujeres que buscaron el atendimiento para realización del examen, en tres Unidades de Salud de Familia. Para la definición del número de participantes, se utilizó el criterio de saturación en cada Unidad de Salud de Familia. La colecta de datos fue realizada por medio de entrevistas, y posteriormente por el análisis temática. Las mujeres presentaron conocimiento acerca del objetivo del examen. Además, afloran sentimientos como la vergüenza y constreñimiento, Ios cuales son construidos cultural mente y se establecen como barreras para la realización de la colecta del citopatológico de colon uterino.

Descriptores: Enfermería; Prevención de cáncer de cuello uterino; Salud de la mujer; Cultura.

\section{INTRODUÇÃO}

A política nacional de atenção integral à saúde da mulher tem como um de seus objetivos específicos reduzir a morbimortalidade por câncer na população feminina. ${ }^{1} 0$ câncer de colo uterino apresenta-se como um dos maiores desafios, pois é uma das neoplasias mais comuns em mulheres brasileiras ${ }^{2}$, sendo o segundo tipo de câncer mais frequente. ${ }^{3}$ Ele se caracteriza como uma doença crônica, na qual ocorrem alterações intraepiteliais, durante um longo período, podendo se transformar em um processo invasivo. ${ }^{4}$ Dessa forma, o seu agravo é progressivo, mas tratável e curável, quando diagnosticado a tempo, o que demanda sucesso na detecção precoce de lesões precursoras. ${ }^{5}$

No Brasil, o exame citopatológico (CP) de colo uterino é a estratégia mais utilizada para detecção prematura desse tipo de neoplasia em mulheres de 25 a 59 anos. $^{3}$ A faixa etária de 35 a 49 anos concentra a maior quantidade de casos positivos da doença ${ }^{6}$ sendo, por isso, considerada faixa etária de risco e para a qual tem-se como meta aumentar em $30 \%$ a cobertura de exames. ${ }^{1}$ Ressalta-se que, quando os resultados apresentam-se nos limites da normalidade, o exame deve ser repetido pelo menos a cada 3 anos. ${ }^{6}$ Em casos de alterações, porém, há necessidade de rever esse prazo, o qual será sempre menor. Esse rastreamento reduz consideravelmente a mortalidade uma vez que logo são tratadas as lesões, permitindo que, após o câncer de pele, esse tipo apresente o maior potencial de prevenção e cura. ${ }^{3}$

Apesar de a coleta do citopatológico de colo uterino ser comprovada como uma técnica efetiva e eficaz, sua cobertura ainda é insuficiente, devido a diversos fatores, tais como: crenças, sentimentos, atitudes e aspectos socioeconômicos. ${ }^{7}$ Exemplo dessa dificuldade é o apontado por estudo com mulheres trabalhadoras. Essa pesquisa revelou que mais de $50 \%$ delas realizaram seu exame citopatológico de colo uterino em serviços particulares ou conveniados e justificam essa procura principalmente pela dificuldade para marcar esse procedimento nas unidades de saúde devido aos horários inadequados. ${ }^{9}$

Por outro lado, a exposição do corpo feminino perpassa por sua construção cultural, a qual está inserida em um longo processo histórico que impõe à mulher certos valores e crenças. ${ }^{10}$ Diversas mulheres não se permitem falar dessas questões, o que pode denotar um interdito cultural. ${ }^{11}$ Nesse contexto, a impessoalidade do procedimento envolve características que fragilizam a prevenção, uma vez que a ideia de expor o corpo faz aflorar sentimentos de vergonha e constrangimento. Outro fator importante refere-se ao estigma que as mulheres constroem diante da incidência de câncer, ou seja, os seus saberes acerca da doença as impedem de realizar o exame por sentirem medo e angústia quanto à possibilidade desse diagnóstico. ${ }^{12}$

Esses saberes sobre o câncer são incorporados no cotidiano dos indivíduos e resultam em ações consideradas práticas sociais. Estas podem apresentar coerência 


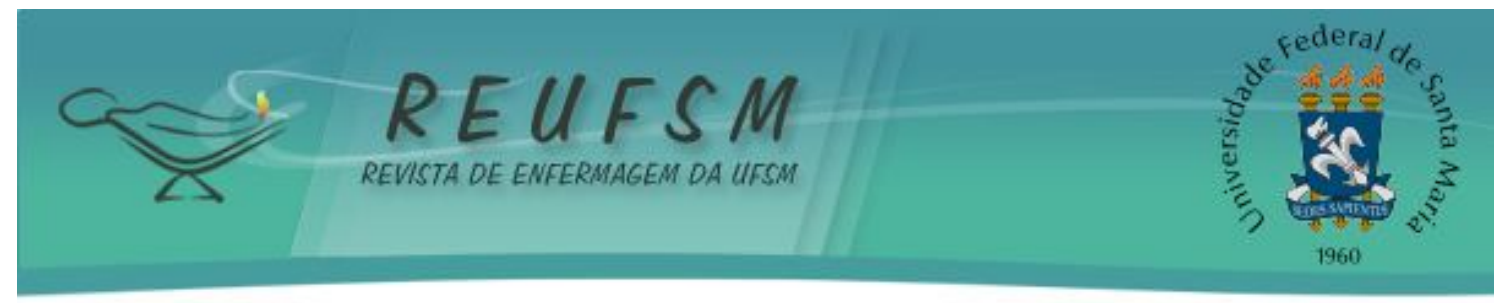

simbólica, porém não absoluta em uma coletividade ou grupo social ${ }^{13}$, o que identifica a presença da cultura. Esta se caracteriza como um conjunto de sistemas entrelaçados de signos e símbolos interpretáveis. É, portanto, um contexto socialmente estabelecido. ${ }^{14}$

Ao considerar a cultura como um constituinte do mundo de cada grupo social, reconhece-se que a questão da saúde e doença encontra-se contida nessa visão do mundo, configurando como instrumento para o profissional de saúde. ${ }^{15}$ Dessa forma, grande parte das mulheres que tem similar construção cultural podem apresentar também opiniões semelhantes quanto à realização do exame citopatológico de colo uterino, pois possuem aspectos culturais definidos e fortemente imbricados no contexto social em que vivem.

Devido a essas questões, surgem numerosos casos da neoplasia de colo de útero diagnosticados em estágio avançado, e com possibilidades de tratamento e cura reduzidos. Tal afirmação pode ser sustentada por pesquisa realizada com mulheres em unidades sanitárias, na qual se constatou que grande parte delas somente procurou o serviço em momentos críticos, quando o corpo já apresentava sintomas associados a doença. ${ }^{12}$ Outros achados destacam a importância da realização de campanhas e ações de planejamento em saúde que preconizem a veiculação de informações e o esclarecimento de questionamentos. ${ }^{7}$

A atual política pública de atenção à saúde da mulher prevê, ainda, dentre as ações necessárias à capacitação de profissionais de saúde para a detecção precoce das lesões, um correto sistema de referência e contrarreferência que facilite o diagnóstico do câncer. ${ }^{1}$ Esse conjunto de fatores inseridos na política pública permeia as estratégias utilizadas pelas três esferas de governo, convertendo-se em referencial para a implementação de diversas ações para as mulheres.

Apesar disso, os profissionais de saúde encontram dificuldades no convencimento de mulheres para a realização do exame, o que fez emergir discussões e inquietações entre enfermeiros assistenciais quanto ao motivo da baixa adesão do público feminino ao citopatológico de colo uterino. Dessa forma, o presente estudo teve como questão norteadora: Quais os saberes e as percepções de mulheres quanto à realização do exame citopatológico de colo uterino? E como objetivo, buscou-se conhecer os saberes e percepções de mulheres quanto à realização do exame citopatológico de colo uterino.

\section{MATERIAIS E MÉTODOS}

Este estudo decorre de uma pesquisa qualitativa, de caráter descritivo e exploratório, realizada com mulheres que coletaram material para o exame citopatológico de colo uterino com enfermeiras durante 0 mês de setembro de 2008 em três unidades de Estratégia de Saúde da Família (ESF), de um município localizado na Região das Missões no Estado do Rio Grande do Sul.

Durante a etapa de coleta de dados, foram entrevistadas 30 mulheres, 10 de cada ESF, que realizaram o exame citopatológico de colo uterino no período da coleta de dados. Em cada ESF, o convite para a participação no presente estudo era estendido a elas, conforme a ordem de atendimento realizado na unidade. Chegou-se ao número 10, em cada ESF, pela saturação dos dados, ou seja, a coleta de dados findou, quando as informações levantadas iniciaram uma sequência de repetição. ${ }^{16}$ Como critérios de inclusão, as mulheres deveriam ser maiores de 18 anos e estarem realizando o exame no período de coleta de dados nas unidades escolhidas. Aquelas mulheres que não se adequaram a esses critérios não participaram da pesquisa.

Respeitando os princípios éticos de uma pesquisa com seres humanos, previstos na Resolução 196/ $96^{17}$, foi lido e entregue o Termo de Consentimento Livre e Esclarecido, em duas vias, uma para o suj eito da pesquisa entrevistado e outra para o pesquisador. Antes de iniciar a etapa de coleta de dados, o projeto de pesquisa foi aprovado, sob no 06804/ PPH/ 08, em 15 de setembro de 2008, pelo Comitê de Ética em Pesquisa da Universidade 


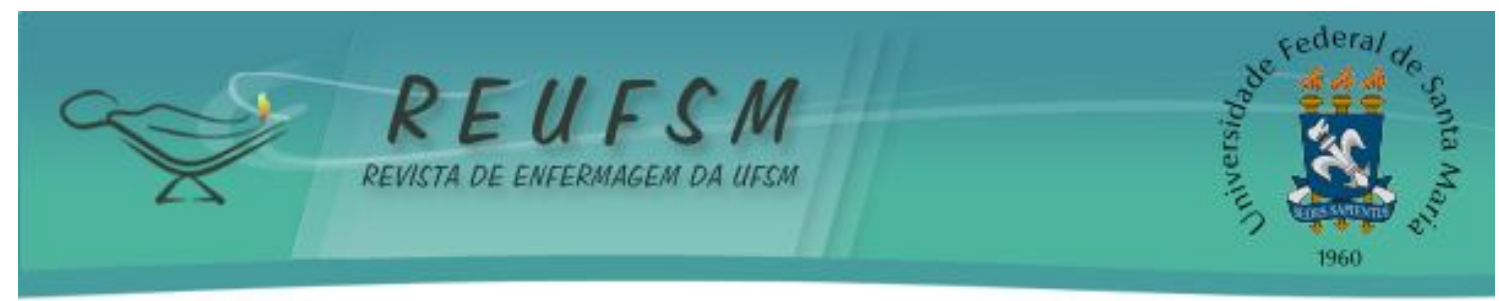

Regional Integrada (URI) - Campus Santo Ângelo/RS. As entrevistas tinham perguntas abertas, as quais permitiram maior liberdade de expressão ${ }^{18}$ sobre as percepções e saberes das mulheres acerca do exame de CP de colo uterino. Para nortear a realização dessa pesquisa, foram utilizados os seguintes eixos: saberes e percepções sobre a coleta de CP de colo uterino e sentimentos na realização do exame. As entrevistas foram realizadas e gravadas na sala de consulta de enfermagem das ESFs. 0 sigilo das participantes do estudo foi preservado por meio da utilização da letra $E$, que corresponde à palavra "entrevistada", seguida do número relacionado à ordem de realização das entrevistas. Como exemplo: E1, E2, e assim sucessivamente.

A análise de dados foi desenvolvida por meio da análise de conteúdo, na modalidade de análise temática, proposta por Minayo, a qual é constituída por três etapas: a Pré-análise, a Exploração do Material, o Tratamento dos Resultados Obtidos e Interpretação. ${ }^{19}$ No primeiro momento, as entrevistas foram transcritas e lidas de maneira exaustiva, buscando reconhecer semelhanças, contradições e repetições. Nessa etapa, foi criada uma legenda de cores, com a finalidade de facilitar a identificação das falas que tinham ideias próximas, bem como reuni-las para a categorização. Assim, o amarelo representou a categoria dos saberes acerca do exame, e o verde, os aspectos psicológicos implicados na realização da coleta de CP de colo uterino.

\section{RESULTADOS E DISCUSSÃO}

Os procedimentos de análise originaram duas grandes categorias: saberes relacionados ao exame citopatológico de colo uterino; aspectos psicológicos e culturais implicados na realização do exame citopatológico de colo uterino, as quais serão descritas na sequência.

\section{Saberes relacionados ao exame citopatológico de colo uterino}

O conhecimento acerca do exame $\mathrm{CP}$ de colo uterino, em relação ao seu objetivo e sua importância, foi visualizado na maioria das falas das mulheres entrevistadas.

Prevenir, evitar se agravar os problemas. Podemos estar com 0 começo de câncer e a gente não sabe. (E5)

Observa-se que, além das informações sobre o objetivo do exame, as entrevistadas demonstraram certo conhecimento quanto às questões relacionadas à doença, como o seu princípio assintomático.

Apesar do conhecimento superficial sobre o câncer, várias mulheres sabem que, por meio desse exame, pode ser encontrada uma doença ${ }^{10}$, mesmo sem sintomatologia inicial aparente. Além disso, os referenciais teóricos sobre a neoplasia de colo de útero revelam que os sinais e sintomas, na fase inicial, raramente são percebidos, ou seja, são silenciosos. ${ }^{20} \mathrm{~A}$ inexistência de sintomas pode ser uma das causas de maior temor frente à possibilidade de câncer, o que, consequentemente, contribui para levar as mulheres à realização da coleta do citopatológico de colo uterino, pois, mesmo que sejam encontradas alterações, pode-se obter maior sucesso com o tratamento precoce.

Neste estudo, demonstrou-se também que algumas mulheres desconhecem a anatomia do corpo feminino, sobretudo o que se relaciona as estruturas como a uretra e o aparel ho reprodutor feminino. Tal afirmação aparece subentendida, conforme a exposição.

O exame é para ver se tenho câncer ou infecção. Tenho dor na bexiga, acho que pode ter algum resultado. (E15) 


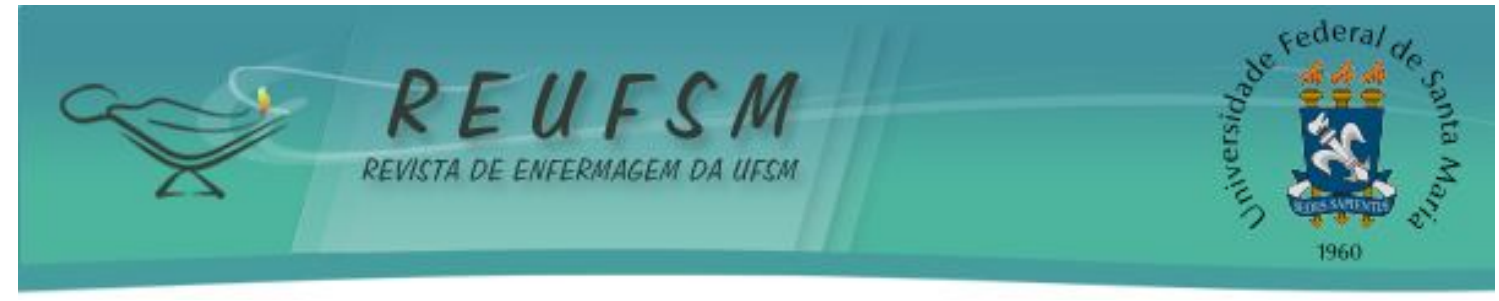

O conhecimento do corpo ainda se apresenta como um desafio para muitas mulheres. Por fatores históricos e culturais, elas foram pouco instigadas para seu autoconhecimento. Uma vez que não são estimuladas desde a infância para conhecer seu corpo, poderão atingir a fase adulta com tabus, mitos e crenças sobre diversas estruturas anatômicas, em especial, sobre seus órgãos reprodutivos.

0 corpo feminino, historicamente, foi bastante regulado por normas e crenças de magia ou religião, que ainda influenciam as questões sexuais. ${ }^{10}$ Tais normas, modos de vida e crenças são definidos como aspectos culturais, que se constituem em estruturas de significados, e se assemelham a teias nas quais o indivíduo, nesse caso a mulher, se encontra socialmente inserido. Os processos que envolvem a cultura podem ser compartilhados, transmitidos e ensinados ${ }^{14} \mathrm{~A}$ cultura oferece a possibilidade de conceber a unidade humana na diversidade de seus modos de vida e de crença. ${ }^{13}$

As crenças também podem conduzir essas mulheres para uma sensação de proteção da doença, dificultando as suas percepções acerca dos fatores de risco que podem prejudicá-las. ${ }^{11} \mathrm{Um}$ estudo realizado no nordeste brasileiro ressalta que, devido a essas características, o fornecimento do exame citopatológico de colo uterino como única ação de prevenção do câncer de colo uterino não é suficiente para assegurar a redução das taxas de mortalidade dessa doença, visto que os efeitos benéficos esperados exigem consciência e real entendimento das mulheres sobre a prática do exame. ${ }^{21}$

Além do pouco conhecimento anatômico de seu próprio corpo, diversas mulheres buscam, por meio do exame, outros diagnósticos, por acreditarem que o citopatológico de colo uterino pode comprovar a existência de doenças como HIV, doenças sexualmente transmissíveis (DSTs) e infecções. Observa-se essa perspectiva em outras falas das entrevistadas, quando se referem ao objetivo do exame.

Serve para constatar se existe alguma doença, o vírus do HIV, a pessoa cuida da saúde, aprende a se conhecer, DST. (E20)

Para prevenir doenças, câncer de colo do útero. Será que aparece AIDS? Aparece infecção vaginal? (E2)

Nesse caso, as mulheres apresentam-se pouco informadas, pois o exame apenas analisa a citologia, detectando alterações nas células do colo do útero. ${ }^{20} \mathrm{Em}$ estudo recente realizado com funcionárias de uma indústria têxtil, acerca do conhecimento do exame citopatológico de colo uterino, pôde-se observar que $27,5 \%$ delas atribuíram ao exame a detecção de doenças, infecções e feridas, sem citar o câncer. ${ }^{4}$ Esses achados retomam, de certa maneira, a cultura que permeia as questões sexuais femininas, pois 0 desconhecimento da real finalidade do exame citopatológico de colo uterino demonstra uma dificuldade ainda presente nas mulheres, pela busca de um diálogo que Ihes permita construir conhecimento concreto a respeito de sua saúde.

Em outra pesquisa ${ }^{7}$ realizada com mulheres, os achados mostraram que $93 \%$ já tinham ouvido falar no exame, mas, destas, $45 \%$ conceituaram de forma equivocada o objetivo do exame. Tais características podem ser atribuídas também a uma distinção pouco clara entre 0 exame ginecológico e o procedimento para a coleta do exame citopatológico, uma vez que, frequentemente, essas mulheres não realizam o exame com o intuito de prevenção, mas porque apresentam queixas. ${ }^{21} \mathrm{O}$ enfermeiro que realiza a coleta do citopatológico de colo uterino deve assumir um papel acolhedor, pois nesse momento ocorre a construção de vínculo, por meio de esclarecimentos e orientações à mulher, bem como troca de informações entre as partes. Essa perspectiva da importância do papel do enfermeiro foi revelada em um estudo acerca dos resultados dos exames de citopatológico de colo uterino, no qual o 


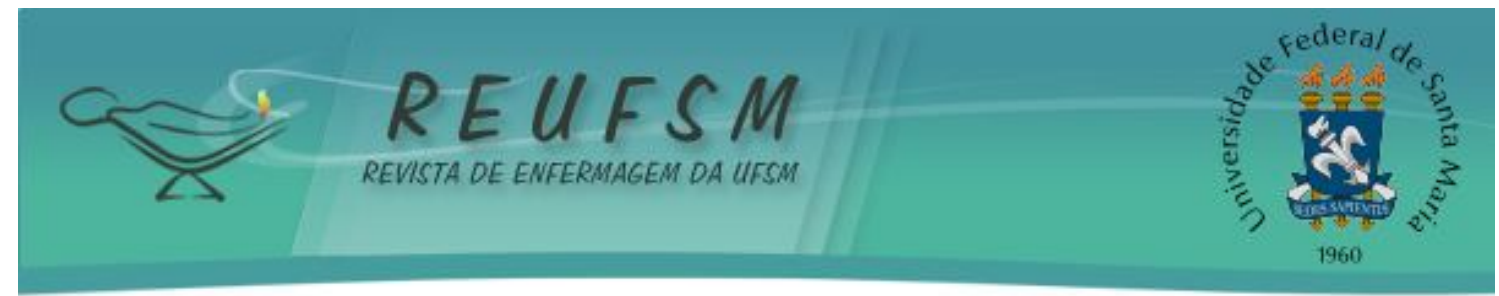

enfermeiro compromete-se em orientar e estimular as mulheres na realização do exame, bem como acompanhar aquelas com diagnóstico alterado, atuando na preservação da qualidade de vida e de saúde delas, por meio de uma assistência personalizada. ${ }^{5}$

\section{Aspectos psicológicos e culturais implicados na realização da coleta do citopatológico de colo uterino}

Um dos sentimentos que emergem, segundo as entrevistadas, durante a realização do exame citopatológico de colo uterino, é a vergonha. Além disso, quando o enfermeiro é do sexo masculino, essa problemática pode ser ainda maximizada. Percebe-se essa perspectiva no discurso a seguir.

Quando é enfermeiro ou médico fico com vergonha de ficar na cama fazendo o exame. (E11)

Não é muito agradável [...] Constrangimento, a maneira que fomos criadas, tímidas, isso é vergonhoso, aquilo é feio. (E23)

A vergonha pode ser sentida, devido à impotência e ao medo em relação à perda do domínio e autonomia sobre o próprio corpo. ${ }^{72}$ A maior identificação com profissionais do sexo feminino pode estar relacionada ao compartilhamento de características anatômicas. ${ }^{4}$ A exposição da mulher ao profissional masculino, além de ser causa do constrangimento, pode ser até mesmo considerada impedimento para a realização da coleta do exame. ${ }^{10}$ Todavia, o exame depende da relação profissional-cliente, pois ele é constrangedor e traz uma série de sentimentos ambíguos, gerando tensão e insegurança quanto ao resultado, independente do profissional de saúde ser homem ou mulher. ${ }^{22}$ Salienta-se ainda que a cultura organiza o mundo social e provê uma visão de mundo às pessoas que a compartilham, orientando, dessa forma, os seus conhecimentos, práticas e atitudes, que envolvem a questão da saúde e da doença. ${ }^{15}$

Essa dificuldade permite a inferência de que os aspectos culturais podem influenciar, pois as questões relacionadas aos valores femininos sempre estiveram subtendidos e permeados por cautela diante da maneira como as mulheres expõem seu corpo. Assim, o atendimento realizado por um profissional masculino pode tornar-se fator que dificulta a realização do exame preventivo de colo de útero, cabendo aos profissionais da equipe prover informações que reflitam melhor a realidade das usuárias, a fim de estabelecer uma relação de confiança e segurança.

A ansiedade também é apontada como outro sentimento que surge durante a realização do exame. A seguir, são observadas tais características.

Sinto-me um pouco nervosa, uma coisa no íntimo. (E7)

A exposição do corpo, por meio de um procedimento invasivo e impessoal, colabora para o aparecimento de sentimentos que dificultam a adesão ao exame citopatológico de colo uterino, como a ansiedade.

Somando-se a isso, os tabus que permeiam as questões sexuais, frente a educação recebida, e também os aspectos culturais familiares podem interferir, uma vez que o sexo ainda é, cotidianamente, ligado à reprodução e ao prazer. ${ }^{10}$

Como se pôde observar, a construção cultural das mulheres na sociedade, não favorece a abordagem de temáticas que se relacionem com a exposição íntima do corpo, pois ainda se detectam dificuldades de adesão das equipes de saúde, quanto à realização de procedimentos que envolvem tais aspectos. Por vezes, a precariedade de informações concretas para as mulheres pode também dificultar esse trabalho, o que vai ao encontro do que já foi exposto. 


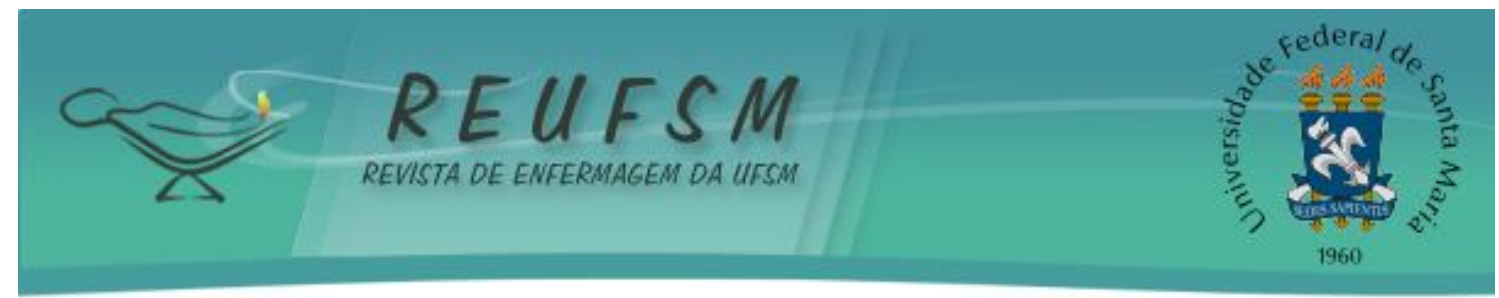

Desse modo, deve-se buscar a compreensão dos aspectos históricos que se interpõem às questões do corpo feminino, para que se obtenham algumas respostas quanto a resistência para a realização do exame preventivo de câncer de colo uterino. ${ }^{2}$ Igualmente, os profissionais devem conhecer a cultura específica das mulheres e seus costumes, atentando para uma educação em saúde efetiva que torne possível explicitação da temática, além da implementação de um exame satisfatório para as partes, podendo contribuir para um adequado planejamento de estratégias, as quais devem ser selecionadas, cuidadosamente, a fim de não causar impactos para a população alvo das atividades de prevenção. ${ }^{11}$

O processo do cuidado é algo que abrange as dimensões inter e intrapessoal, alicerçado em diversos fatores que conduzem ao bem-estar psíquico, orientado pelos princípios da mutualidade, da participação efetiva e compartilhada. Esses princípios permitem reciprocidade no cuidado, diálogo, motivação, confiança e construção de vínculos. ${ }^{23}$

0 presente trabalho reforça aos enfermeiros e profissionais de saúde a necessidade de conhecer os saberes e as percepções que as mulheres possuem quanto à realização do exame citopatológico de colo uterino, a fim de favorecer o comprometimento desses profissionais com as reais demandas individuais e coletivas da população.

\section{CONCLUSÃO}

Pode-se dizer que muitos foram os avanços na área da saúde. É necessário, porém, empreender ações mais efetivas, as quais devem estar relacionadas com os aspectos culturais imbricados no contexto em que as mulheres se encontram. Para que ocorra maior adesão de mulheres ao exame preventivo de colo uterino, deve-se considerar aspectos associados à desmistificação do câncer de colo uterino, bem como da realização do exame.

Neste estudo, salienta-se que o conhecimento dos saberes e das percepções das mulheres acerca da coleta do citopatológico de colo uterino aproxima os profissionais de saúde à realidade das usuárias do sistema de saúde, conduzindo-os para novas posturas práticas frente ao atendimento a essa parcela da população.

Essa maior aproximação poderá permitir ações de educação em saúde mais eficazes, favorecendo um diálogo de compreensão entre os profissionais e usuárias, bem como 0 atendimento às demandas locais. Além disso, possibilita um planejamento das ações de prevenção ao câncer de colo uterino com vistas à produção e troca de conhecimentos sobre essa temática.

\section{REFERÊNCIAS}

1. Brasil. Ministério da Saúde. Política nacional de atenção integral à saúde da mulher: plano de ação 2004-2007. Secretaria de Atenção a Saúde. Departamento de ações programáticas estratégicas. Brasília (DF); 2004.

2. Cruz LMB, Loureiro RP. A comunicação na abordagem preventiva do câncer do colo do útero: importância das influências histórico-culturais e da sexualidade feminina na adesão às campanhas. Saúde soc. 2008 jun; 17(2): 120-31.

3. Brasil. Ministério da Saúde. Instituto Nacional de Câncer. Estimativa 2010: Incidência de câncer no Brasil. Rio de J aneiro (RJ ); 2009.

4. Ferreira MLM, Oliveira C. Conhecimento e significado para funcionárias de indústrias têxteis sobre prevenção do câncer do colo-uterino e detecção precoce do câncer da mama, Rev bras cancerol. 2006 mar; 52(1): 5-15. 


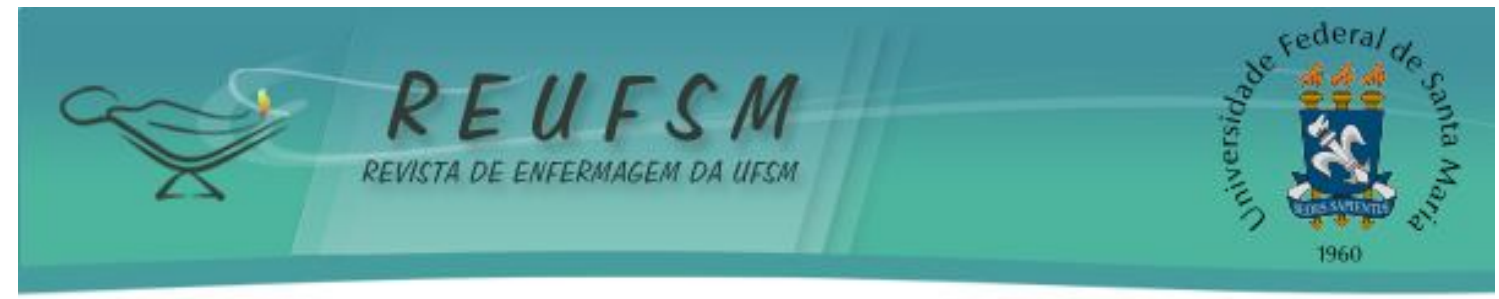

5. Guimarães J V et al. Freqüência de alterações cérvico-vaginais em mulheres submetidas ao exame citopatológico. Rev eletrônica enferm. 2007; 9(3): 815-20.

6. Brasil. Ministério da Saúde. Prevenção do câncer de colo de útero. Manual Técnico, Profissionais de Saúde. Brasília (DF); 2002.

7. Rodrigues Neto J F, Figueiredo MFS, Siqueira LG. Exame citopatológico do colo do útero: fatores associados a não realização em ESF. Rev eletrônica enferm. 2008; 10(3): 610-21.

8. Oliveira MM, Pinto IC. Percepção das usuárias sobre as ações de Prevenção do Câncer do Colo do Útero na Estratégia Saúde da Família em uma Distrital de Saúde do município de Ribeirão Preto (SP), Brasil. Rev bras saúde materno-infant. 2007; 7(1):31-8.

9. Domingos ACP, Murata IMH, Pelloso SM, Schirmer J, Carvalho MDB. Câncer do colo do útero: comportamento preventivo de auto-cuidado à saúde. Ciênc cuid saúde. 2007; 6(suplem. 2):397-403.

10. Duavy LM, Batista FLR, J orge MSB, Santos J BF. A percepção da mulher sobre o exame preventivo do câncer cérvico-uterino: estudo de caso. Cienc saúde colet. 2007 maio-jun; 12(3): $733-42$.

11. Lee EE. Korean american women's beliefs about breast and cervical cancer and associated symbolic meanings. Oncol nurs forum. 2007 mai;34(3): 713-20.

12. Thum M, Heck RM, Soares MC, Deprá AS. Câncer de colo uterino: percepção das mulheres sobre prevenção. Cienc cuid saude. 2008 out-dez; 7(4):509-16.

13. Cuche D. A Noção de cultura nas ciências sociais. 2a ed. Tradução de Viviane Ribeiro. Bauru: EDUSC; 2002.

14. Geertz C. A interpretação das culturas. Rio de J aneiro: Guanabara-Koogan; 1989. p.13-41.

15. Langdon EJ, Wiik FB. Antropologia, saúde e doença: uma introdução ao conceito de cultura aplicado às ciências da saúde. Rev latinoam enferm. 2010 mai-jun; 18(3): [09 telas].

16. Fontanella BJ B, Ricas J, Turato ER. Amostragem por saturação em pesquisas qualitativas em saúde: contribuições teóricas. Cad saúde pública. 2008 jan; 24(1): 17-27.

17. Brasil. Ministério da Saúde. Conselho Nacional de Saúde. Resolução no 196, de 10 de Outubro de 1996. Brasília: Ministério da Saúde, 1996.

18. Fontanella BJ B, Campos CJG, Turato ER. Coleta de dados na pesquisa clínicoqualitativa: uso de entrevistas não dirigidas de questões abertas por profissionais da saúde. Rev latinoam enferm. 2006. set - out; 14(5):812-20.

19. Minayo MCS, Deslandes SF, Gomes R. Pesquisa social: teoria, método e criatividade. $28^{a}$ ed. Petrópolis (RJ): Vozes; 2009.

20. Smeltzer SC, Bare BG. Histórico e tratamento: problemas relacionados aos processos reprodutivos femininos. In: Smeltzer SC, Bare BG, editors. Brunner e Suddarth: Tratado de enfermagem médico-cirúrgica, $11^{a}$ ed. v. 2. Rio de Janeiro: Guanabara Koogan; 2009. p. 1137-69.

21. Fernandes JV et al. Knowledge, attitudes, and practices related to Pap test by women, Northeastern Brazil. Rev saúde publica. 2009 out; 43(5): 851-8.

22. Merighi MAB, Hamano L, Cavalcante LG. O exame preventivo do câncer cérvico-uterino: conhecimento e significado para as funcionárias de uma escola de enfermagem de uma instituição pública. Rev Esc Enferm USP. 2002; 36(3): 289-96. 


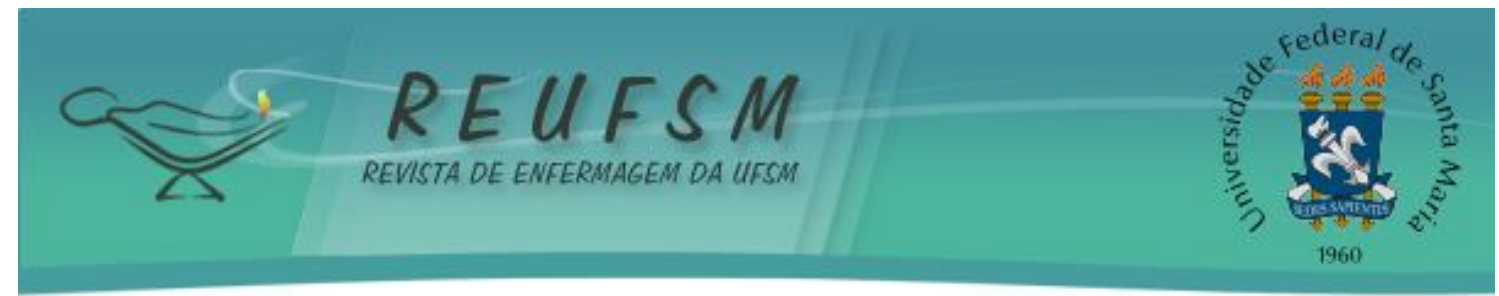

23. Saupe R, Geib LTC. A Pedagogia do Cuidado In: Nietsche EA (org.). O processo Educativo na Formação e na Práxis dos Profissionais da Saúde: Desafios Compromissos e Utopias. Santa Maria (RS): UFSM; 2009 p. 143-163.

Data de recebimento: 09/02/2011

Data de aceite: 11/05/2011

Contato com autora responsável: Simone Wünsch

Endereço: Rua Júlio de Castilhos 3113, Centro, São Luiz Gonzaga, RS.

CEP: $97800-000$.

E-mail: simone.wunsch@gmail.com 